
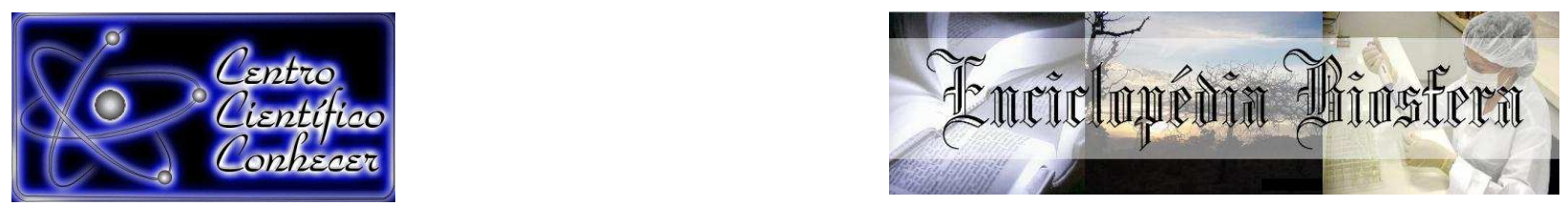

\title{
AVALIACÃO DA INTERFERÊNCIA DOS PARÂMETROS DE ELETRODEPOSIÇÃO NOS NÍVEIS DE ABSORÇÃO DE SUPERFÍCIES SELETIVAS
}

\author{
Ithyara Dheylle Machado de Medeiros ${ }^{1}$, José Felix da Silva Neto ${ }^{2}$, Kerolayne Santos \\ Leite $^{3}$, Aline Karla Barbosa da Silva ${ }^{3}$, Kelly Cristiane Gomes ${ }^{2}$ \\ ${ }^{1}$ Doutoranda do Programa de Pós-Graduação em Engenharia Mecânica, UFPB - \\ João Pessoa - Brasil, ithyaramachado@gmail.com \\ ${ }^{2}$ Professor(a) Doutor(a) na Universidade Federal da Paraíba, Centro de Energias \\ Alternativas e Renováveis \\ ${ }^{3}$ Mestranda do Programa de Pós-Graduação em Engenharia Mecânica, UFPB
}

Recebido em: 02/10/2017 - Aprovado em: 21/11/2017 - Publicado em: 05/12/2017 DOI: 10.18677/EnciBio_2017B114

\begin{abstract}
Superfícies seletivas são revestimentos superficiais presentes em coletores solares e fabricados com materiais que apresentam boas propriedades absortivas na faixa espectral da irradiação solar, e simultaneamente baixa emissividade na faixa espectral relativa à emissão de calor por radiação nas temperaturas de operação desses coletores. O presente trabalho se propôs a analisar como a modificação dos parâmetros (tempo e distância ânodo-cátodo) da eletrodeposição pode influenciar na absorção da superfície seletiva de cromo negro produzida, e correlacionar a absorção obtida com a espessura e homogeneidade dos revestimentos. Ao final do estudo, foi possível concluir que a modificação dos parâmetros da eletrodeposição pode influenciar na absorção da superfície seletiva absorvedora produzida, de forma que os parâmetros de menor distância $(5 \mathrm{~cm})$ e menor tempo ( $5 \mathrm{~min})$ foram os que mais interferiram positivamente na técnica. Já ao ser estabelecida a relação entre a absorção obtida com a espessura e homogeneidade dos revestimentos, percebeuse que sob as condições do presente estudo não há uma associação entre eles.
\end{abstract}

RESUMO

PALAVRAS-CHAVE: Eletrodeposição, espessura, superfícies seletivas.

\section{EVALUATION OF THE INTERFERENCE OF ELECTRODEPOSITION PARAMETERS IN THE LEVELS OF ABSORPTION OF SELECTIVE SURFACES}

\begin{abstract}
Selective surfaces are surface coatings present in solar collectors and manufactured with materials that have good absorptive properties in the spectral range of the solar irradiation, and simultaneously low emissivity in the spectral range relative to the emission of heat by radiation in the operating temperatures of these collectors. The present work aimed to analyze how the modification of the electrodeposition parameters (time and anode-cathode distance) can influence the absorption of the selective black chromium surface, and to correlate the absorption obtained with the thickness and homogeneity of the coatings. At the end of the study, it was possible to
\end{abstract}


conclude that the modification of the electrodeposition parameters could influence the absorption of the selective absorber surface, so that the parameters of shorter distance $(5 \mathrm{~cm})$ and shorter time $(5 \mathrm{~min})$ were the ones that interfered positively in the art. When the relation between the absorption obtained with the thickness and homogeneity of the coatings was established, it was noticed that under the conditions of the present study there is no association between them.

KEYWORDS: selective surfaces, electrodeposition, thickness.

\section{INTRODUÇÃO}

As fontes alternativas e renováveis de energia tais como energia solar, eólica e da biomassa, têm adquirido relevância, inclusive com o desenvolvimento e a consolidação de pesquisas acerca do emprego destas formas de energia a nível mundial (BERIZZI et al., 2015; UECKERDT et al., 2015; VOINOV et al., 2015).

A Alemanha, e alguns outros países, como os Estados Unidos já apresentam uma porcentagem relevante de sua matriz energética proveniente de fontes renováveis de energia (EIA, 2015; ISE-FRAUNHOFER, 2015). No Brasil, embora os níveis de irradiação solar permaneçam, durante todo o ano, entre os maiores do mundo (TIBA et al., 2000; PEREIRA et al., 2006), a parcela correspondente ao aproveitamento da energia proveniente da conversão da radiação solar representa uma parcela reduzida da matriz energética nacional (ANEEL, 2014; EPE, 2015).

A forma mais prática e rápida de se utilizar a energia solar é por meio da conversão térmica. Embora a conversão solar térmica exiba um bom custo-benefício (SANI et al., 2012), o emprego desse aproveitamento é limitado quando o objetivo é 0 aquecimento de fluidos em coletores de média (entre $100^{\circ} \mathrm{C}$ e $400^{\circ} \mathrm{C}$ ) e alta (acima de $400^{\circ} \mathrm{C}$ ) temperaturas. Esse fato é em decorrência do fenômeno de emissão/perda da radiação, pois quanto maior for a temperatura de trabalho do coletor solar maior será a quantidade de calor emitida (INCROPERA; WITT, 2014), isso está relacionado aos materiais dos quais são fabricados os coletores, uma vez que esses não apresentam estabilidade térmica nessas faixas de temperatura.

Como a emissão de calor por radiação é um fenômeno de superfície (INCROPERA; WITT, 2014), Tabor (1961) e outros autores (KOKOROPOULOS et al., 1959; SHAFFER, 1958) sugeriram o revestimento superficial dos coletores solares com materiais com boas propriedades absortivas na faixa espectral da irradiação solar, e simultaneamente baixa emissividade na faixa espectral relativa à emissão de calor por radiação nas temperaturas de operação desses coletores. Esses revestimentos receberam o nome de superfícies seletivas absorvedoras (SSA's).

Desde então, vários autores têm se preocupado em aprimorar a eficiência dos coletores solares, por meio de estudos que envolvam a modificação da técnica, da matéria prima e dos parâmetros de fabricação do filme. Uma dessas técnicas, utilizadas comercialmente, é a eletrodeposição, que quando aplicada para a produção de revestimentos a base de cromo negro apresenta algumas vantagens em relação as demais, tais como a estabilidade térmica $\left(400^{\circ} \mathrm{C}\right.$ no vácuo e $350^{\circ} \mathrm{C}$ no ar), baixa emissividade $(0,03-0,10)$ e alta absortância $(0,88-0,97)$ (KENNEDY, 2002; SELVAKUMAR; BARSHILIA, 2012).

No estudo de Sheu et al. (2016) foram produzidos revestimentos de cromo negro eletrodepositados durante um minuto sobre substratos de aço em um processo com variação de densidade de corrente, objetivando identificar a dimensão da espessura do filme em função da densidade de corrente empregada. Através das 
análises realizadas foi possível perceber que as espessuras variaram de 0,23-1,98 $\mu \mathrm{m}$ para densidades entre 10-50 A/dm².

Por meio da utilização da mesma técnica, Surviliene et al. (2014) produziram superfícies seletivas de cromo negro em substratos de aço utilizando $40 \mathrm{~A} / \mathrm{dm}^{2}$ de densidade de corrente e $2,5 \mathrm{~cm}$ de distância ânodo-cátodo. Essas superfícies apresentam níveis de absorção entre $98,8-99,3 \%$ na faixa de comprimento de onda entre 350-1100 $\mathrm{nm}$ e espessura de 3,2 $\mu \mathrm{m}$.

Diante do cenário apresentado, percebe-se que as pesquisas envolvendo produção de superfícies seletivas a base de cromo negro por eletrodeposição estão voltados para modificação dos parâmetros da eletrodeposição (densidade de corrente, distância ânodo-cátodo, tempo), no entanto, a maioria só modifica uma variável. Dessa forma, o presente estudo se propôs a analisar como a variação de dois parâmetros associados (distância ânodo-cátodo e tempo) pode influenciar nos níveis de absorção da superfície seletiva absorvedora fabricada, e correlacionar a absorção obtida com a espessura e homogeneidade dos revestimentos.

\section{MATERIAL E MÉTODOS}

O presente estudo cumpriu o planejamento experimental ilustrado na Figura 1.

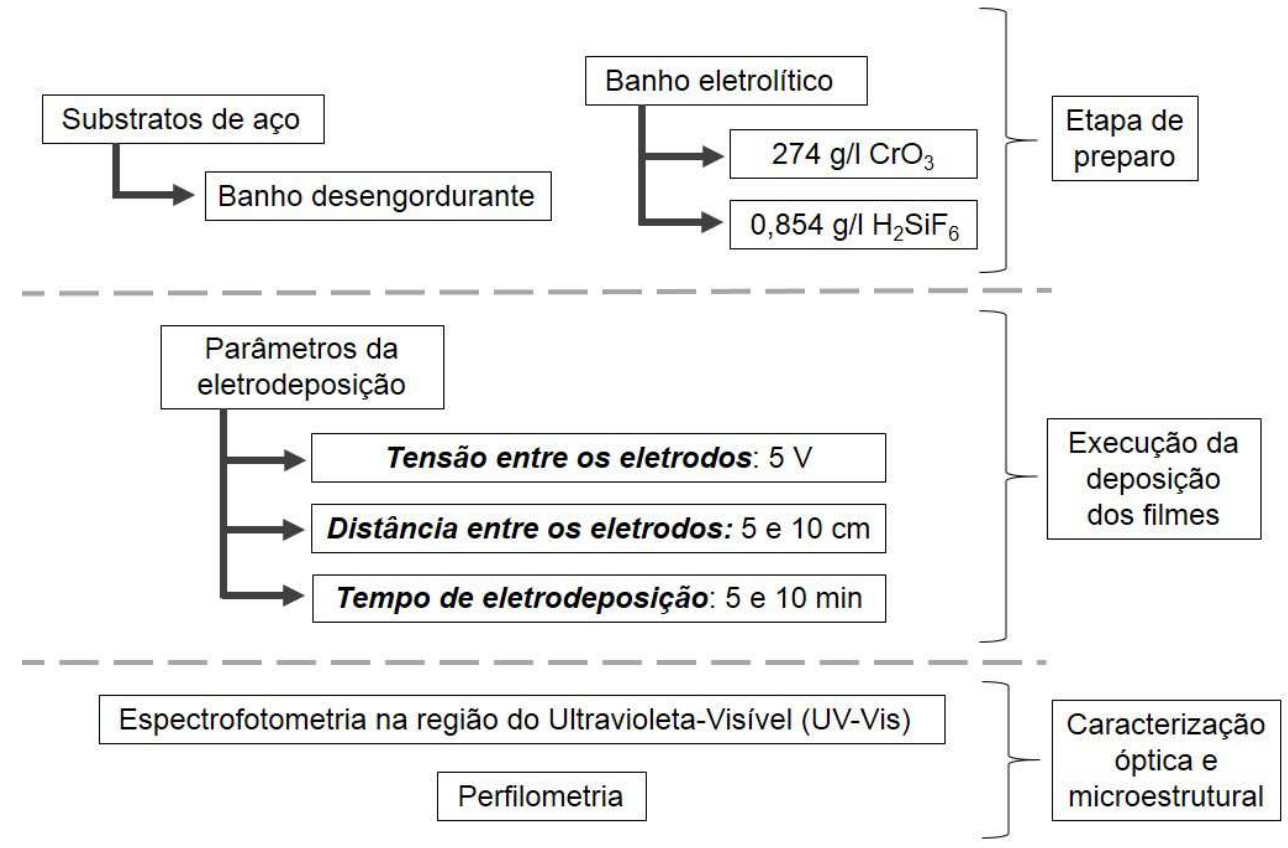

FIGURA 1. Planejamento experimental da pesquisa. Fonte: Autores (2017).

De acordo com a Figura 1, percebe-se que a pesquisa foi dividida em três etapas: (i) Preparo, (ii) Execução, e (iii) Caracterização. Na etapa de preparo foi realizada a limpeza dos substratos de aço e a composição do banho eletrolítico, na etapa seguinte foi executada a eletrodeposição de quatro filmes de cromo negro, em triplicata, sob condições variadas de distância entre os eletrodos e tempo de eletrodeposição, já na terceira etapa houve a caracterização das SSA's obtidas. O esquema das variáveis envolvidas na obtenção das superfícies e a nomenclatura que foi adotada para cada uma dessas, em função dos parâmetros utilizados, pode ser observada na Figura 2. 


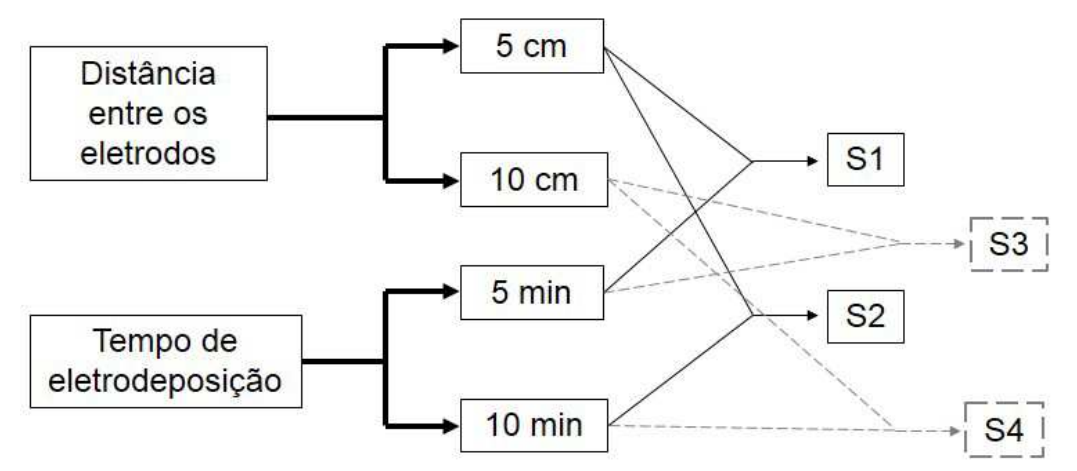

FIGURA 2. Nomenclatura das Superfícies (S) obtidas por eletrodeposição. Fonte: Autores (2017).

Os substratos utilizados para a deposição dos filmes absorvedores foram de aço inoxidável AISI 304, com dimensões de $3 \mathrm{~cm} \times 2,5 \mathrm{~cm}$. A Figura 3 ilustra 0 substrato antes e após a eletrodeposição.

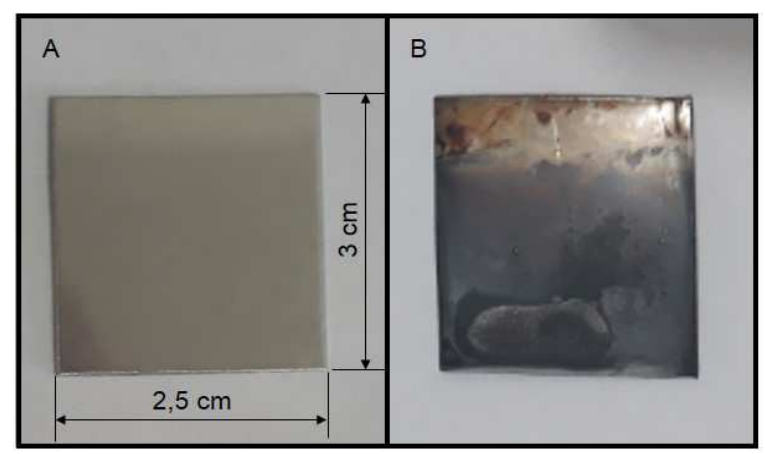

FIGURA 3. A) Substrato de aço inoxidável AISI 304 antes da eletrodeposição, B) Após a eletrodeposição. Fonte: Autores (2017).

Antes de serem submetidos ao processo de eletrodeposição os substratos ficaram imersos por 30 minutos em uma solução aquecida à $50^{\circ} \mathrm{C}$ de $0,77 \mathrm{~kg} / \mathrm{l}$ de ácido cítrico $\left(\mathrm{C}_{6} \mathrm{H}_{8} \mathrm{O}_{7}\right)$. Em seguida, passaram por um banho ultrassônico de 15 minutos, com posterior secagem em estufa à $50^{\circ} \mathrm{C} / 1 \mathrm{~h}$.

Após essa etapa, ocorreu a composição do banho eletrolítico segundo a solução expressa na Figura 2. O esquema do sistema de eletrodeposição pode ser visualizado na Figura 4, o ânodo utilizado para fechar o circuito elétrico foi uma liga $\mathrm{Pb}-\mathrm{Sb}(95-5 \%)$.

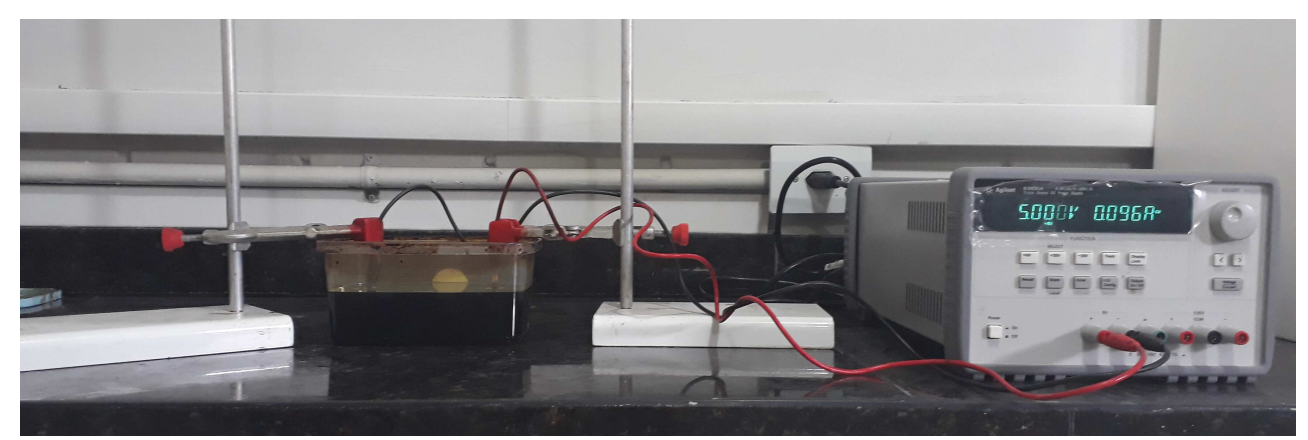

FIGURA 4. Sistema de banho eletrolítico. Fonte: Autores (2017).

O acesso as propriedades ópticas dos filmes absorvedores de cromo negro depositados sobre substratos de aço inoxidável foi obtido através da utilização do ENCICLOPÉDIA BIOSFERA, Centro Científico Conhecer - Goiânia, v.14 n.26; p.1363 
Espectrofotômetro na região do Ultravioleta-Visível (UV-Vis) da marca Shimadzu modelo UV-2600 operando na região de 220 a $1400 \mathrm{~nm}$ com medidas de absortância, utilizando o acessório esfera de integração o qual possibilita a análise de filmes.

As amostras passaram também por análise de superfície através de aparelho de perfilometria óptica sem contato (CCI MP, Taylor Hobson, Inglaterra) conectado a uma unidade computadorizada contendo o software Talysurf CCl (Taylor Hobson, Inglaterra) para obtenção e análise dos dados.

\section{RESULTADOS E DISCUSSÃO Espectrofotometria na região do Ultravioleta-Visível (UV-Vis)}

Após a eletrodeposição, os revestimentos obtidos foram submetidos ao UVVis, objetivando identificar qual obteve o maior nível de absorção. A Figura 3 esquematiza a resposta em porcentagem de absortância que cada uma das SSA's produzidas obteve.

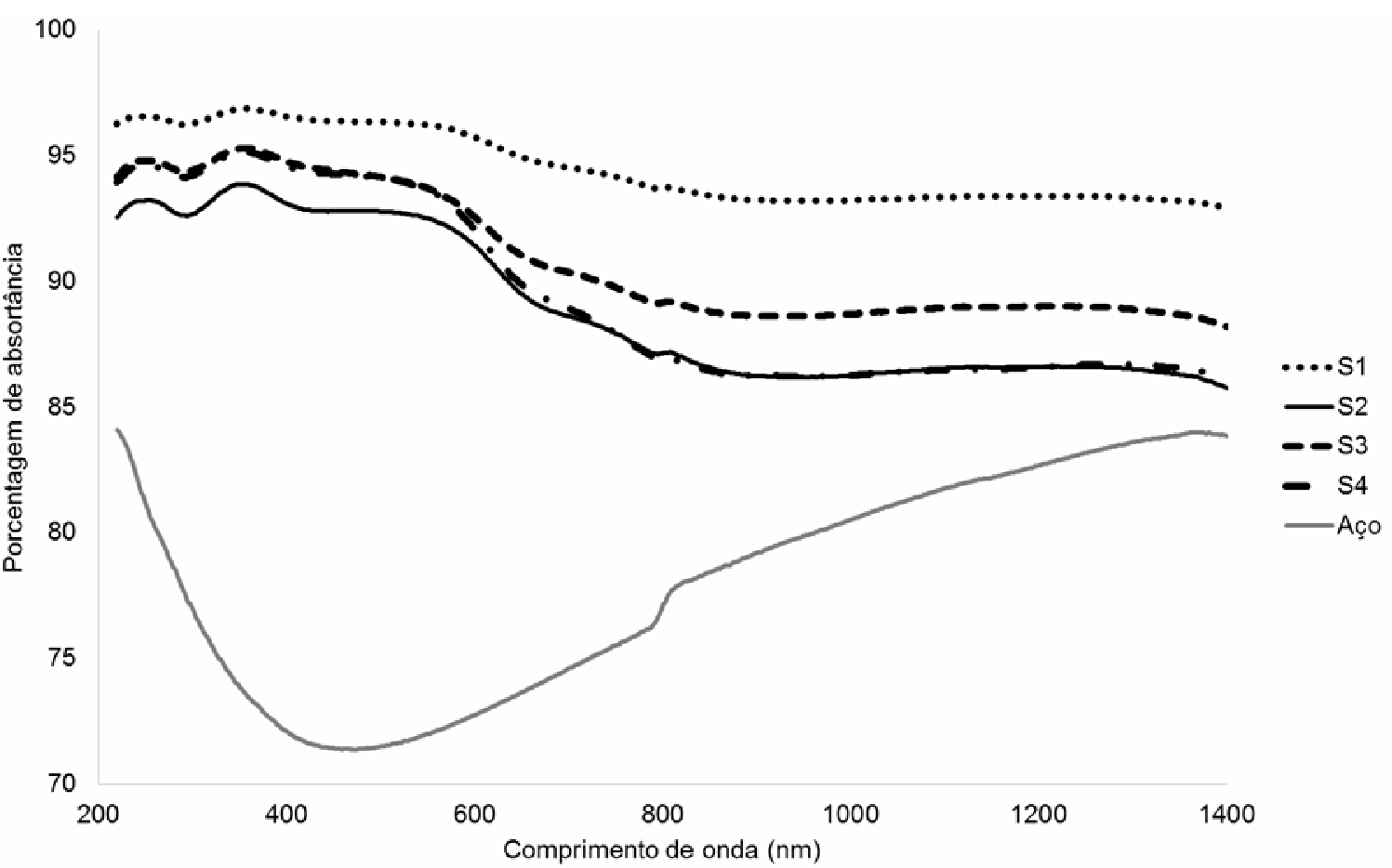

FIGURA 3. Porcentagem de absortância dos filmes. Fonte: Autores (2017).

Tendo em vista que o objetivo dos filmes produzidos é obter maiores níveis de absorção e estabilidade absortiva ao longo do espectro em estudo (200-1400 nm) (KOKOROPOULOS et al., 1959). Nota-se, pela Figura 3, que a eletrodeposição realizada por 5 min e com os eletrodos separados a uma distância de $5 \mathrm{~cm}$ (variáveis correspondente a amostra S1) foi a que obteve os melhores resultados, ou seja, os parâmetros de menor distância e menor tempo foram os que mais influenciaram positivamente a técnica da eletrodeposição sob as condições em análise, fato corroborado pelo estudo de Daryabegy e Mahmoodpoor (2006) que determinaram a faixa de 0,5-5 min como o tempo apropriado para a eletrodeposição de cromo negro.

Como a amostra S2 foi a que obteve a pior resposta em termos do objetivo esperado, percebe-se que 0 tempo de eletrodeposição foi significativo para 0 
processo, uma vez que esse foi o parâmetro que diferenciou S1 e S2. Fato confirmado através da Figura 4, na qual é possível observar que houve uma diminuição de 5,61\% na média de absorção entre as superfícies S1 e S2.

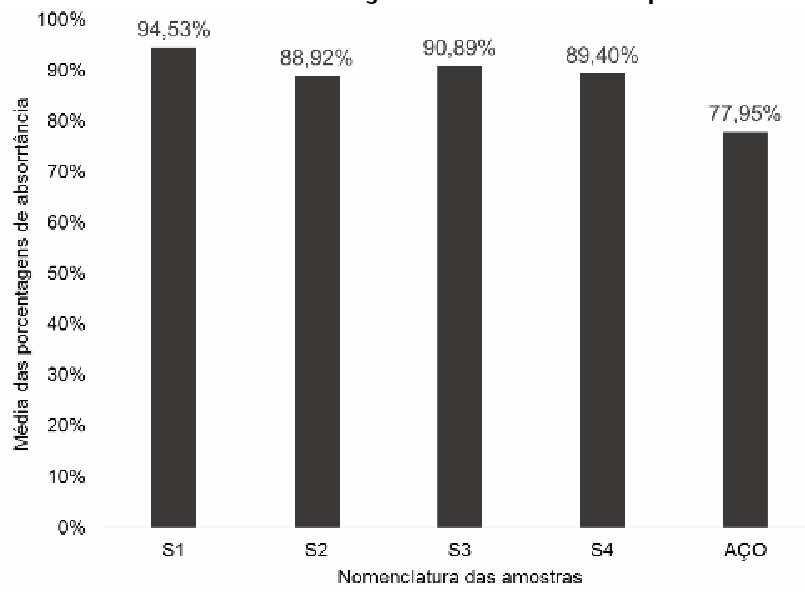

FIGURA 4. Média de absortância dos filmes.

Fonte: Autores (2017).

As superfícies seletivas produzidas por Lee (2007), utilizando a distância ânodo-cátodo de $5 \mathrm{~cm}$, apresentaram absortância de $80 \%$, no entanto, a faixa do espectro estudada foi de $200-2500 \mathrm{~nm}$. Uma vez que os maiores níveis de absorção do filme ocorrem na faixa de $200-1400 \mathrm{~nm}$, os valores encontrados no presente estudo correspondem ao esperado.

\section{Perfilometria de superfície}

Após a determinação dos níveis de absorção dos filmes, os mesmos foram submetidos a análise de Perfilometria, objetivando estipular a espessura dos revestimentos produzidos. Esses dados estão expostos na Tabela 1 a seguir.

TABELA 1. Espessura dos filmes. Fonte: Autores (2017).

\begin{tabular}{ccc}
\hline Amostra & Espessura $(\mu \mathrm{m})$ & $\begin{array}{c}\text { Média de } \\
\text { absortância }(\%)\end{array}$ \\
\hline S1 & 5,8 & 94,53 \\
S2 & 2,73 & 88,92 \\
S3 & 19,3 & 90,89 \\
S4 & 1,92 & 89,40 \\
\hline
\end{tabular}

Percebe-se que não houve uma relação entre o aumento e a diminuição da espessura com os níveis de absorção obtidos, tendo em vista que S1 (com espessura mediana) foi o que apresentou o melhor resultado como SSA. Essa relação não pôde ser verificada uma vez que a pesquisa teve por enfoque analisar a influência da modificação de mais de um parâmetro de eletrodeposição, fato que impossibilita o estabelecimento de uma associação entre espessura e nível de absorção.

No entanto, as espessuras determinadas corroboram com a literatura pertinente, a exemplo de Xiao et al. (2011) que fabricaram filmes com variação de 1,8-6,58 $\mu \mathrm{m}$, e Bayati et al. (2005) que depositaram cromo negro com espessuras de 1,99-16,63 $\mu \mathrm{m}$. A distribuição do filme sobre o substrato pode ser visualizada através da Figura 5. 


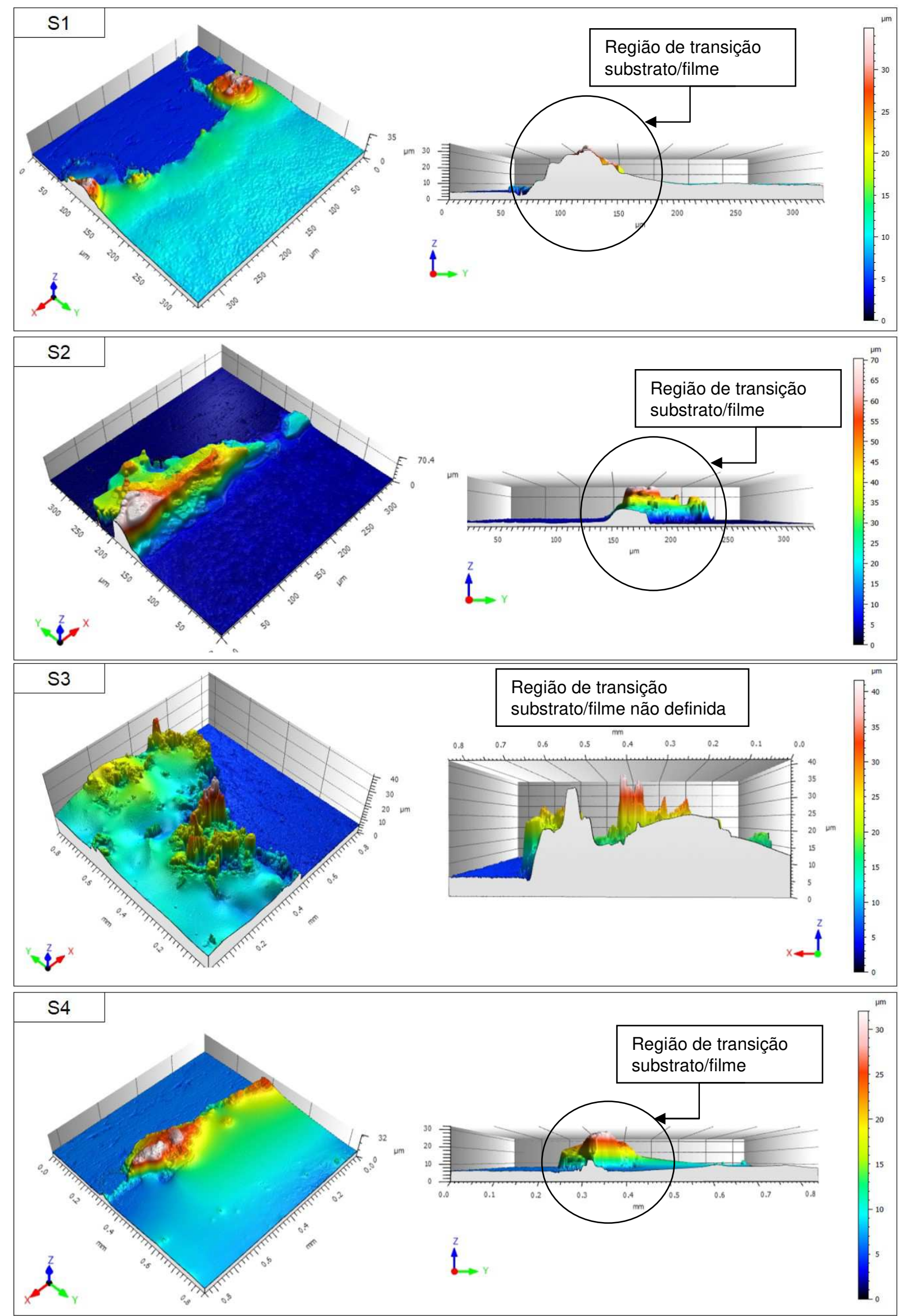

FIGURA 5. 3D e vista lateral da transição substrato/filme. Fonte: Autores (2017). ENCICLOPÉDIA BIOSFERA, Centro Científico Conhecer - Goiânia, v.14 n.26; p.1366 
Pela Figura 5, nota-se que as amostras S1 e S4 foram as que obtivem maior homogeneidade do filme sobre o substrato e uma região de transição substrato/filme bem definida. No entanto, essa homogeneidade não se mostrou como fator determinante para obtenção de uma maior absorção na faixa do espectro examinado no presente estudo, fato esperado uma vez que os parâmetros de trabalho (tempo e distância ânodo-cátodo) variaram para cada amostra em análise.

A homogeneidade e o aspecto morfológico dos filmes ilustrados na Figura 5 estão condizentes com a pesquisa de Lee (2007), que realizou microscopia de força atômica em seus revestimentos seletivos a base de cromo negro, e que se mostraram semelhantes aos obtidos no presente estudo.

\section{CONCLUSÃO}

Diante do exposto, pode-se concluir que a modificação dos parâmetros da eletrodeposição pode influenciar na absorção da superfície seletiva absorvedora produzida, de forma que os parâmetros de menor distância $(5 \mathrm{~cm})$ e menor tempo (5 min) foram os que mais influenciaram positivamente a técnica da eletrodeposição sob as condições em análise. Ao ser estabelecida a relação entre a absorção obtida com a espessura e homogeneidade dos revestimentos, percebeu-se que sob as condições do presente estudo não há uma associação entre eles.

\section{REFERÊNCIAS}

ANEEL - Agência Nacional de Energia Elétrica. Relatório ANEEL 2013. Brasília, 2014.

BAYATI, M. R.; SHARIAT, M. H.; JANGHORBAN, K. Design of chemical composition and optimum working conditions for trivalent black chromium electroplating bath used for solar termal collectors. Renewable Energy, v. 30, n. 14, p. 2163-2178, 2005. Disponível em: <https://doi.org/10.1016/j.renene.2005.02.003>.doi: 10.1016/j.renene.2005.02.003

BERIZZI, A.; BOVO, C.; ILEA, V.; MERLO, M.; MIOTTI, A.; ZANELLINI, F. Decentralized congestion mitigation in HV distribution grids with large penetration of renewable generation. Electrical Power and Energy Systems, v. 71, p. 51-59, 2015. Disponível em: <https://doi.org/10.1016/j.ijepes.2015.02.023>.doi: 10.1016/j.ijepes.2015.02.023

EIA - U.S. Energy Information Administration. Total Energy, 2015. Disponível em: $<$ http://www.eia.gov/totalenergy/data/monthly/index.cfm\#summary>. Acesso em 22 de setembro de 2017.

EPE - Empresa de Pesquisa Energética. Balanço Energético Nacional 2015: Anobase 2014. Rio de Janeiro, 2015.

INCROPERA, F. P.; WITT, D. P. Fundamentos da transferência de calor e massa, 7ª Edição. Rio de Janeiro. LTC, 2014.

ISE - FRAUNHOFER. Stromerzeugung aus Solar- und Windenergie im Jahr 2014. Disponível em: https://www.ise.fraunhofer.de/de/downloads/pdf-files/data-nivc/stromproduktion-aus-solar-und-windenergie-2014.pdf. Acesso em 22 de setembro 
de 2017.

LEE, K. D. Preparation and characterization of black chrome solar selective coatings. Journal of the Korean physical society, v. 51, n. 1, p. 135-144, 2007. Disponível em:< https://doi.org/10.3938/jkps.51.135>.doi: 10.3938/jkps.51.135.

PEREIRA, E.B.; MARTINS, F.R. ; ABREU, S.L.; RÜTHER, R. Atlas brasileiro de energia solar. INPE. São José dos Campos, 2006.

KENNEDY, C. E. Review of Mid- to High-Temperature Solar Selective Absorber Materials, NREL/TP-520-31267, National Renewable Energy Laboratory, Colorado, July 2002.

KOKOROPOULOS, P.; SALAM, E.; DANIELS, F. Selective radiation coatings preparation and high temperature stability. Solar Energy, v. 3, n. 4, p. 19-23, 1959. Disponível em: <https://doi.org/10.1016/0038-092X(59)90003-9>.doi: 10.1016/0038092X(59)90003-9.

SANI, E.; MERCATELLI, L.; JANFRANCESCO, D.; SANS, J. L.; SCITI, D. Ultra-high temperature ceramics for solar receivers: spectral and high-temperature emittance characterization. Journal of the European optical society-rapid publications, v. 7, p. 1-5, 2012. Disponível em: <http://dx.doi.org/10.2971/jeos.2012.12052>.doi: 10.2971/jeos.2012.12052.

SELVAKUMAR, N.; BARSHILIA, H.C. Review of physical vapor deposited (PVD) spectrally selective coatings for mid- and high-temperature solar thermal applications. Solar Energy Materials \& Solar Cells, v. 98, p. 1-23, 2012. Disponível em: < https://doi.org/10.1016/j.solmat.2011.10.028>.doi: 10.1016/j.solmat.2011.10.028.

SHAFFER, L.H. Wavelength-dependent (selective) processes for the utilization of solar energy. Solar Energy, v. 2, n. 3, p. 21-26, 1958. Disponível em: < https://doi.org/10.1016/0038-092X(58)90050-1 >.doi: 10.1016/0038-092X(58)90050-1

SHEU, H.; LU, C.; LEE, H.; PU, N.; WU, P.; HSIEH, S.; GER, M. Electrodeposition of black chromium-cobalt alloy based on trivalente sulfate electrolyte. Journal of the Taiwan Institute of Chemical Engineers, v. 59, p. 496-505, 2016. Disponível em: < https://doi.org/10.1016/j.jtice.2015.08.002>.doi: 10.1016/j.jtice.2015.08.002

SURVILIENE, S.; CESUNIENE, A.; JUSKENAS, R.; SELSKIENE, A.; BUCINSKIENE, D.; KALINAUSKAS, P.; JUSKEVICIUS, K.; JUREVICIUTE, I. The use of trivalente chromium bath to obtain a solar selective black chromium coating. Applied Surface Science, v. 305, p. 492-497, 2014. Disponível em: < https://doi.org/10.1016/j.apsusc.2014.03.122>.doi: 10.1016/j.apsusc.2014.03.122.

TABOR, H. Solar collectors, selective surfaces and heat engines. Proceedings of the National Academy of Sciences of the United States of America, v. 47, p. 1271-1278, 1961. Disponível em: < http://www.pnas.org/content/47/8/1271.short >. Acesso em: 25 de setembro de 2017. 
TIBA, C.; FRAIDENRAICH, N.; MOSZKOWICZ, M.; CAVALCANTI, E.S.C.; LYRA, F. J. M.; NOGUEIRA, A. M. B.; GROSSI, H. G. Atlas Solarimétrico do Brasil. Recife, Pernambuco: Editora Universitária - UFPE, 2000.

UECKERDT, F.; BRECHA, R.; LUDERER, G. Analyzing major challenges of wind and solar variability in power systems. Renewable Energy, v. 81, p.1-10, 2015. Disponível em: <https://doi.org/10.1016/j.renene.2015.03.002>.doi: 10.1016/j.renene.2015.03.002.

VOINOV, A.; ARODUDU, O.; DUREN, I.V.; MORALES, J.; QIN, L. Estimating the potential of roadside vegetation for bioenergy production. Journal of Cleaner Production, v. 102, p. 213-225, 2015. Disponível em: < https://doi.org/10.1016/j.jclepro.2015.04.034>.doi: 10.1016/j.renene.2015.03.002.

XIAO, X.; MIAO, L.; XU, G.; LU, L.; SU, Z.; WANG, N.; TANEMURA, S. A facile process to prepare copper oxide thin filmes as solar selective absorbers. Applied Surface Science, v. 257, n. 24, p. 10729-10736, 2011. Disponível em:< https://doi.org/10.1016/j.apsusc.2011.07.088 >.doi: 10.1016/j.apsusc.2011.07.088 